\title{
The Great 16th-Century Chroniclers of Pyrotechnology
}

Go to any good technical library today and you will find an ocean of journals, monographs, proceedings, CD databases, manuals, and other sources loaded with protocols, practices, formulae, and procedures for virtually every industrial art. This plethora of information is all the more reason why last year's passing without at least some acknowledgment in the MRS Bulletin of the 500th anniversary of George Bauer's birth might fit into the genre of ungracious acts.

Bauer, a physician in sixteenth-century Bohemia and Saxony (now areas of the Czech Republic and Slovakia and of Germany, respectively) is better known by historians as Georgius Agricola, a Latinized name probably given to him by his instructors. His achievement most important to today's materials community is that he was one of the very first to write a detailed and comprehensive chronicle of the practical arts, primarily mining and metallurgy. Various ancient writers had recorded bits and pieces on such topics much earlier. But none of these approached the comprehensiveness or currency of Agricola's most celebrated work De Re Metallica, which was first published in 1556, a year after the author's death. Besides mining and metallurgy, the treatise covers glassmaking, pottery, and the manufacture of salt, soda, potash, saltpeter (potassium nitrate), and other chemicals, which Agricola called "solidified juices."

De Re Metallica, with dozens of beautiful and detailed woodcuts, went through 10 editions and several translations at a time when printing such a lavish book was a major undertaking. It remains one of the most important primary sources on Medieval and Renaissance technology for contemporary historians of technology. Interestingly, it was first translated into English in 1912 by none other than the engineer and U.S. President-to-be Herbert Hoover and his wife Lou Henry Hoover.

The late Manhattan Project metallurgist and materials historian Cyril Smith pointed out that the Italian metallurgist and writer Vannoccio Biringuccio, who was born in 1480, was unjustly overshadowed by Agricola. In 1540, while Agricola was still working on De Re Metallica, Biringuccio's De La Pirotechnia, was published. Indeed, Smith goes so far as to say that in several places in De Re Metallica Agricola verges on plagiarism. The relatively greater familiarity with Agricola compared with Biringuccio may be due to the former's more scholarly approach. His use of Latin would have naturally attracted the intelligentsia. Biringuccio wrote in the Italian vernacular to reach his technical audience. To be fair, De Re Metallica did include far better illustrations than $\mathrm{De} L a$ Pirotechnia, and often provided more technical detail. Still, in his translation with Martha Teach Gnudi of Biringuccio's work, Smith credits Biringuccio's work with marking "the beginning of a true technological literature, with both craftsmanship and science united by a writer's pen to form a record of an important facet of man's achievement as a stimulus to further advance."

Regardless of the priority issue, the sober presentations of these two writers stand out starkly against a vast background of feverish, thickly coded works by alchemists, whose goals were riches and/or spiritual purification rather than furthering the pyrotechnical arts. (Ironically, Isaac Newton, during his own extensive alchemical pursuits, sometimes summoned "an old mouldy Book," which a secretary of the great scientist identified as De Re Metallica.) In the estimation of science historian A. Rupert Hall, Agricola and Biringuccio "represented the true summation of 6000 years of development in the pyrotechnic arts."

As Agricola wrote in Book I (of a dozen), he spent 20 years researching and writing De Re Metallica to defend metals, which others were maligning at the time as evil materials that humanity ought not to want or try to procure. The mining industry was under attack for such injuries as tearing up the landscape and killing off workers, and for being too uncertain to ensure reliable economies for the towns supporting the operations. "When ores are washed, the water which has been used poisons the brooks and streams, and either destroys fish or drives them away," he wrote in his portrayal of the critics' arguments. "The inhabitants of these regions, on account of the devastation of their fields, find great difficulty in procuring necessities of life."

Metal brought out the worst in people, too. Consider the precious metals. "It is almost our daily experience that, for the sake of obtaining gold and silver, doors are burst open, walls are pierced, wretched travelers are struck by rapacious and cruel men born to theft, sacrilege, invasion and robbery," he wrote. The most deadly fruit of human ingenuity, he continued by way of a quote from the Roman historian Pliny, "For to bring Death to men more quickly we have given wings to iron and taught it to fly.'" The resemblance to modern day debates about guns is conspicuous.

As a champion of metals and materials, however, Agricola then attempted to upend all of that metal-brought carnage with a litany of good that metals do in society. "But has the artisan or weaver of clothes any instrument not made of iron?" Agricola asked his readers. It serves as vessels for making agricultural tools like plows and scythes; for making tools out of other materials like wood; for preparing wool, flax, feather, hair, fur, and leather for clothing. Indeed, he concluded, "If there were no metals, men would pass a horrible and wretched existence in the midst of wild beasts: they would return to the acorns and fruits and berries of the forest." With this as his motivation, he then devoted the bulk of the book to describing the various practices that people of the day used for locating, assaying, mining, preparing, and smelting metallic ores, as well as the means of refining and working the iron, copper, tin, lead, bismuth, antimony, mercury, gold, and silver that came of such labors.

Just what Agricola thought about the physical nature of metals does not come out clearly in De Re Metallica. In a footnote, the Hoovers point out that Agricola followed an Aristotelian theory in which metals are a mixture of water (which is why they can melt and flow) and an "earth," the different metals derived from differing proportions and purities of water and earth.

Throughout De Re Metallica are fascinating passages that reveal the montage of beliefs swarming simultaneously within even the most highly educated Renaissance minds. Agricola was generally skeptical about supernatural claims and magical abilities claimed by the alchemy community, which was then still thriving. Still, he believed in the reality of demons. Mines are sometimes abandoned, he 
Reproduced from G. Agricola, De Re Metallica, translated by H.C. Hoover and L.H. Hoover, Dover, New York, 1950, p. 383.

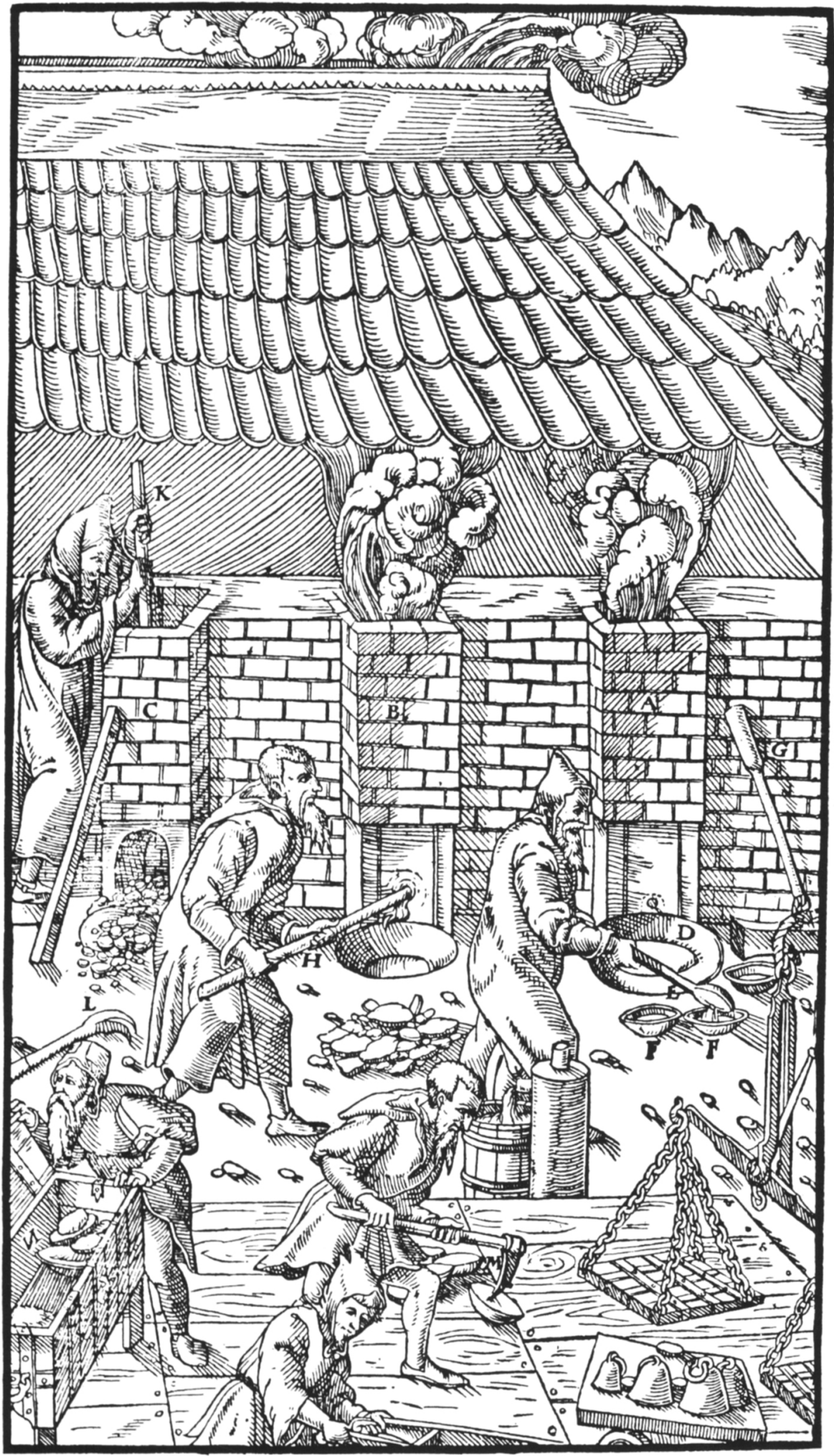

A, B, C-Three furnaces. At The first stands the smelter, who with a ladle POURS THE ALLOY OUT OF THE FOREHEARTH INTO THE MOULDS. D-FOREHEARTH. E-Ladle. F-Moulds. G-Round wooden rammer. H-Tapping-bar. At the SECOND FURNACE STANDS THE SMELTER, WHO OPENS THE TAP-HOLE WITH HIS TAPPING-BAR. THE ASSISTANT, STANDING ON STEPS PLACED AGAINST THE THIRD FURNACE WHICH HAS BEEN BROKEN OPEN, CHIPS OFT THE aCcRetions. I-STEPS. K-SPatula. L-The Other HOOKED BAR. M-MINE CAPTAIN CARRYING A CAKE, IN WHICH HE HAS STUCK THE PICK, TO THE SCALES TO BE WEIGHED. N-ANOTHER MINE CAPTAIN OPENS A CHEST IN WHICH HIS THINGS ARE KEPT. claimed, because of the presence of "demons of ferocious aspect," which "are expelled and put to flight by prayer and fasting." In his work De Animantibus, he briefly wrote about a kindlier class of mine denizens. "They appear to laugh with glee and pretend to do much, but really do nothing," he wrote, adding helpfully that "sometimes they throw pebbles at the workmen, but they rarely injure them unless the workmen ridicule or curse them."

Besides the work of Agricola and Biringuccio, there were a few other lesser sixteenth-century works about mining, metallurgy, and mineralogy, including a set of German booklets-called Probierbuchlein-filled with procedural recipes written more for practitioners than for the wider readership that Agricola and Biringuccio sought. The dearth of early literature on materials manufacturing is understandable. Artisans were not generally inclined toward writing nor did they want to reveal trade secrets; those educated enough to write rarely had the practical arts on their minds. Agricola and Biringuccio broke through this mutual exclusivity. Their legacy has grown into endless buckling stacks of library shelves filled with writings of those who make things.

IVAN AMATO

FOR FURTHER READING: Georgius Agricola, De Re Metallica, translated by Herbert Clark Hoover and Lou Henry Hoover, Dover Publication, Inc., (New York: 1950); A. Rupert Hall, The Revolution in Science 1500-1750, Longman (New York: 1983); Biringuccio Vannoccio, De La Pirotechnia, translated by Cyril Stanley Smith and Martha Teach Gnudi, Dover Publications, Inc. (New York, 1990).

\section{New Videotape "The Golden Age
of Crystal Defects"} Available from MRS

Contact MRS Publications for Details

(412) 367-3012

Fax: (412) 367-4373 